\title{
PELATIHAN TEKNIK PENGOLAHAN DAN PENGEMASAN PRODUK MAKANAN BERBAHAN DASAR UBI DI BIBIS BARUKELURAHAN NUSUKAN KECAMATAN BANJARSARI SURAKARTA
}

\author{
Endang Sri Suwarni ${ }^{1)}$, Murni Sulistyowati ${ }^{2)}$, V. Titi Purwantini ${ }^{3)}$ \\ Dosen Manajemen, STIE-AUB Surakarta ${ }^{1)}$,Dosen Akuntansi, STIE-AUB Surakarta ${ }^{2)}$, \\ Dosen Manajemen, STIE-AUB Surakarta ${ }^{3)}$ \\ E-mail: endangss@gmail.com ${ }^{1)}$,sulistyowati@yahoo.com ${ }^{2)}$, \\ veronica_purwantini@ \\ yahoo.co.id ${ }^{3)}$
}

\begin{abstract}
Devotion to the Community about Training on Processing Techniques and Packaging of Ubi jalar based Food Products in Bibis Baru, kalurahan Nusukan Kecamatan Banjarsari Surakarta targeted by craftsmen and The Family Welfare community. The purpose of this devotion activity is to provide counseling and training on the processing and packaging techniques of sweet potato based products at BibisBaruKelurahanNusukanKecamatanBanjarsari Surakarta. The method used in this Devotion activity is the lecture method on the processing and packaging techniques of sweet potato based products so that the participants are the craftsmen group and The Family Welfare community can directly engage in practice and creating utilize sweet potato to become food products with the look and taste that tempting the taste, As well as worth selling so that it can increase family income and develop into a promising business in the future. The target after the training is quite encouraging $60 \%$ of the training objectives are achieved and the rest needs to be followed up with mentoring for subsequent Community Service.

Keywords : Sweet potatoes, processing and packaging, food product
\end{abstract}

\begin{abstract}
ABSTRAKS
Pengabdian Kepada Masyarakat tentang Pelatihan Teknik Pengolahan dan Pengemasan Produk Makanan Berbahan dasar Ubi di Bibis Baru Kelurahan Nusukan Kecamatan Banjarsari Surakarta dengan sasaran kelompok pengrajin dan Ibu-ibu PKK. Tujuan kegiatan pengabdian ini adalah memberikan penyuluhan danpelatihan tentang teknik pengolahan dan pengemasan produk makanan berbahan dasar ubi di Bibis Baru Kelurahan Nusukan Kecamatan Banjarsari Surakarta. Metode yang digunakan dalam kegiatan Pengabdian ini adalah metode ceramah tentang teknik pengolahan dan pengemasan produk makanan berbahan dasar ubiagar para peserta yaitu kelompok pengrajin dan Ibu-ibu PKK dapat langsung terlibat berlatih dan berkraeasi memanfaatkan ubi menjadi produk makanan dengan tampilan dan rasa yang menggoda selera, serta layak jual sehingga dapat meningkatkan pendapatan keluarga dan berkembang menjadi usaha yang menjanjikan pada masa mendatang. Target setelah dilaksanakan pelatihan cukup menggembirakan $60 \%$ tujuan pelatihan tercapai dan sisanya perlu ditindak lanjuti dengan pendampingan untuk Pengabdian Kepada Masyarakat berikutnya.
\end{abstract}

Kata kunci : Ubi, pengolahan dan pengemasam. Produk makanan

\section{PENDAHULUAN}

Letak geografis kota Surakarta berada pada suatu dataran rendah yaitu pada cekungan lereng pegunungan Lawu dan pegunungan Merapi dengan ketinggian kurang lebih $92 \mathrm{~m}$ di atas permukaaan air laut, berbatasan dengan Kabupaten Klaten, Wonogiri, Boyolali, Sukoharjo, Sragen Dan Karanganyar. Kota yang juga populer dengan sebutan Solo atau Sala ini merupakan kota terbesar ketiga di Jawa bagian selatan setelah Bandung dan Malang.dan merupakan pewaris kesultanan Mataram yang dipecah melalui perjanjian Giyanti pada tahun1755 bersama kota Yogyakarta. Kemakmuran dan kemashuran kota Surakarta sejak dulu samapai kini, hingga terabadikan dalam satu lagu keroncong yang sangat populer "Bengawan Solo" karya besar sang legendaris maestro keroncong Gesang.Kota yang memiliki semboyan mulat sarira angrasa wanidan slogan umum 
berseri (akronim bersih sehat rapi indah) serta slogan pariwisata The spirit of Java inimemiliki luas wilayah $44 \mathrm{~km}^{2}$ terdiri dari 5 kecamatan dan 51 kelurahan dengan jumlah penduduk mencapai 503.421 jiwa (sumber: wikipedia th.2010) dan tingkat kepadatan penduduk tertinggi di Jawa Tengah yaitu $11.370 \mathrm{jiwa} / \mathrm{km}^{2}$ ( kepadatan Jawa Tengah hanya $992 \mathrm{jiwa} / \mathrm{km}^{2}$. Selain dikenal sebagai kota sejarah, pariwisata, budaya dan kebersihannya, dengan tingkat pertumbuhan ekonomi kota Surakarta juga cukup tinggi dan menyajikan untuk tujuan investasi. Beragam industri tumbuh cukup pesat.

Bibis Baru adalah salah satu wilayah RW dalam Kelurahan Nusukan Kecamatan Banjarsari Surakarta yang merupakan salah satu wilayah utara Surakarta yang berbatasan dengan Kabupaten Karanganyar dan Kabupaten Boyolali, komposisi peduduknya49,4\% laki-laki dan 50,6\% perempuan, Mayoritas mata pencaharian penduduk adalah buruh kurang lebih $30,77 \%$, tingkat pendidikan terbanyak lulus SLTA 34,5\%, dan mayoritas beragama Islam 90,86\% dan 62,4\% adalah usia produktif (Laporan Monografi Dinamis Kelurahan Nusukan Kecamatan Banjarsari bulan Agustus 2016)

Mengamati situasi dan kondisi warga Kelurahan Nusukan yang mayoritas berada pada golongan usia produktif $(62,4 \%)$ sudah semestinya kita berpikir positif bahkan tersenyum lega karena ini berkaitan dengan pendapatan yang diterima per Kepala Keluarga untuk memenuhi berbagai kebutuhan hidup sehari-harinya. Namun apabila dilihat dari prosentase mata pencahariannya $42,54 \%$ menengah ke bawah ( petani, buruh dan pedagang kecil dan menengah) sebesar maka ini berarti masih banyak penduduk dengan pendapatan minimal sampai tingkat UMR.

Dalam upaya membantu menambah pendapatan keluarga , para istri /ibu-ibu warga Bibis Baru mengambil peran aktif dengan bekerja meskipun kebanyakan dari mereka dengan berbekal pendidikan dan ketrampilan seadanya. Beberapa waktu lalu banyak yang mengambil job dengan menjadi penjahit borongan namun upah yang terlalu kecil membuat mereka mencari terobosan lain dengan menjadi pemetik dan penyortir lombok/cabe untuk dipasok ke bebeapa perusahaan sambal saus botol. Namun itu ternyata tak berberlangsung lama dan mereka nilai kursng menjanjikan karena ketidak stabian harga dan pasokan lombok/cabe sehingga mereka kembali mencoba berjualan warungan atau membuat beberapa kue dan makanan untuk disetorkan dan dijual di warung atau wedangan angkringan yang penghasilannya tidak cukup memadai untuk menopang kebutuhan seharihari yang makin tinggi seiring mahalnya biaya hidup dan biaya pendidkan anak yang makin tinggi.

Kota Solo yang dikenal dengan surganya kuliner dan melimpahnya produk pertanian dari beberapa kabupaten sekitar Surakarta menginspirasi Tim Pengabdian Kepada Masyarakat untuk menawarkan solusi setelah melalui pengamatan situasi mendengarkan keluhan dan keinginan ibu-ibu PKK dan Kelompok Usaha Rumahan (home industry) untuk bangkit memperbaiki kondisi ekonomi keluarganya, tidak tau harus membuat dan menjual produk makanan apa yang cukup menjual (madolke dalam bahasa Jawa).Gayung pun bersambut, ibu- ibu PKK dan kelompok industri rumahan antusias menyambut uluran tangan kai Tim engabdian Kepada Masyarakat.

Berangkat dari analisis situasi itulah Tim Pengabdian Kepada Masyarakat menawarkan solusi untuk mengolah aneka produk makanan berbahan dasar ubi yang banyak dijumpai di pasar tradisional dan harganya cukup murah menjadi produk makanan bergizi, bercita rasa, sederhana bahan, alat dan proses pembuatannya agar bisa tampil lebih enak, mewah, cantik dan menarik serta bernilai ekonomis sehingga diharapkan bisa menambah pendapatan keluarga dengan tetap melestarikan bahan-bahan olahan alami hasil produksi lokal. Salah satu bahan yang dipilih adalah ubi jalar, dengan beberapa varietas seperti ubi jalar putih, kuning, maupun ubi jalar ungu.yang banyak dipasok dari Ngargoyoso, Tawangmangu dan daerah lain di Kabupaten Karanganyar.

Bentuk kegiatan pengabdian ini adalah penyuluhan dan pelatihan dengan peragaan atau demo /praktik kepada ibu-ibu PKK dan Kelompok Usaha Rumahan untuk mengolah bahan dasar ubi yang dipadukan dengan bahan dasar lain mejadi beberapa jenis produk makanan 
kue kering seperti nastar, soes kering, stick ubi ungu, kue moci, bakpia ataupun kue basah seperti brownies, donat, sponge cake, chiffon cake, Bolu, pie, talam, onde-onde, klepon, putu ayu, puding,bubur candil, kue lumpur, cup cake, muffin getuk lindri, bolu kukus dan kreasi kue berbahan ubi lainnya.

Suatu keharusan untuk memikirkan secara serius bagaimana pengolahan ubi yang murah, kurang tahan lama dan melimpah, Tim Pengabdian Kepada Masyarakat juga menawarkankan alternatif lain yaitu pelatihan pengolahan ubi menjadi tepung ubi dan mie berbahan organik ubi dari beberapa varietas ubi putih, kuning dan ungu pada kesempatan kegiatan pengabdian yang akan datang..Dari kegiatan ini diharapkan berhasil membuka peluang usaha yang menjanjikan pada khalayak sasaran.

\section{METODE}

Berdasarkan survei dan pengamatan Tim Pengabdian Kepada Masyarakat setelah melakukan analisis situasi pada masyarakat khususnya pada Ibu-ibu PKK dan sekelompok usaha rumahan (home industry) di Bibis Baru Kelurahan Nusukan Kecamatan Banjarsari Surakarta yang menanyakan bagaiamana mengolah, mengemas dan memasarkan produk makanan berbahan dasar ubi agar tidak monoton, lebih variatif, bernilai gizi, tampil dalam sajian dan kemasan yang lebih cantik dan menarik serta bernilai ekonomis lebih tinggi, maka kegiatan Pengabdian Kepada Masyarakat ini dilaksanakan dalam bentuksebagai berikut:

\section{Presentasi}

Memberikan ceramah dan penyuluhan tentang kandungan gizi yang terdapat pada berbagai jenis ubi, bagaimana teknik pengolahan dan pengemasan produk makanan berbahan dasar ubi sehingga lebih variatif, menarik, dan bernilai ekonomis tanpa mengurangi kandungan gizi dan manfaatnya kepada ibu-ibu PKK dan kelompok usaha rumahan (home industry) di Bibis Baru Kelurahan Nusukan Kecamatan Banjarsari Surakarta.

2. Peragaan dan Pembagian alat/bahan.

Memperagakan, mempraktikkan dan memberikan pelatihan kepada Ibu-ibu PKK dan kelompok usaha rumahan (home industry) bagaimana mengolah produk ubi menjadi aneka produk makanan yang lebih variatif, bergizi dan bercita rasa tinggi dengan tampilan yang lebig cantik dan menarik serta dikemas dalam kkemasan yang higienis dan menarik sehingga diharapkan mampu meningkatkan nilai jual dan ekonomis produk olahan tersebut. Ubi yang biasanya hanya diolah menjadi produk makanan yang terkesan tradisional dan hanya dikenal lokal seperti ubi rebus, ubi goreng, timus, talam, ceriping /keripik, dan sejenisnya kini saatnya dikembangkan dengan kreativitas dan lebih variatif menjadi olahan kue cantik dan bercita rasa serta bernilai jual dan ekonomis yang tinggi baik kue kering maupun kue basah. Aneka kue kering berbahan dasar ubi misal nastar ubi, kaastangel ubi, soes kering ubi, stick ubi dan sebagainya. Sedangkan kue basah berbahan dasar ubi misalnya brownies ubi, soes ubi, puding ubi, spong cake /bolu ubi, chiffon cake ubi, donat ubi dan sebagainya. Selanjutnya memperagakan bagaimana nenyajikan dan teknik pengemasannya untuk dipasarkan kepada konsumen.

\section{HASIL PEMBAHASAN DAN DAMPAK}

A. Teknik Pengolahan Produk makanan Berbahan Dasar Ubi Jalar Sebagaimana kita lihat dan jumpai pada mayoritas masyarakat Indonesia, selama ini pengolahan, penyajian dan pengemasan produk makanan berbahan dasar ubi jalar di kalangan ibuibu PKK dan kelompok usaha rumahan (home industry) maupun masyarakat pada umumnya hanya dlakukan secara sederhana, diolah menjadi kue tradisional khas makanan lokal serta penyajian dan pengemasannya pun ala kadarnya, sehingga kurang variatif , kurang menarik dan membosankan,padahal sesungguhnya ubi dapat menjadi bahan dasar untuk diolah menjadi beragam kue yang enak, bernilai gizi tinggi dan menarik. Oleh sebab itu Tim Pengabdian tergerak hati untuk turun tangan membantu 
Ibu-ibu PKK dan Kelompok Usaha Rumahan (home industry) di Bibis Baru mengembangkan kreativitas dalam mengolah , menyajikan dan mengemas aneka produk makanan berbahan dasar ubi agar lebih variatif, menarik dan bernilai ekonomis.

Kami Tim Pengabdian Kepada Masyarakat (PKM STIE AUB Surakarta menawarkan beberapakegiatan Pengabdian Kepada Masyarakat sebagai berikut :

1. Memberikan peragaan /praktik dan pelatihan teknik mengolah aneka produk makanan berbahan dasar ubi menjadi kue-kue yang enak, bergizi, bernilai ekonomis dengan performa lebih variatif, cantik dan menarik.

2. Memberikan pelatihan teknik penyajian dan pengemasan aneka produk makanan berbahan dasar ubi agarpenampilan, penyajian dan pengemasannya bertahan lebih lama dan menarik.

Produk Makanan berbahan dasar ubijalar saat ini mulai banyak dilirik, karena rasa dan indahnya cara penyajian. Sebelumnya barangkali orang kurang tertarik dan berminat mencobanya, namun faktanya kini kue , snack, roti, pastry dan banyak makanan olahan berbahan dasar ubi jalar banyak diminati, tidak jarang ada pula yang terus mencoba dan bereksperimen mengembangkan usaha nya di bidang kuliner, sekadarnguri-uri kebudayaan melalui kuliner hingga terus berinovasi dan memodifikasikan aneka produk makanan berbahan dasar ubi jalar berbagai varian atau jenis, baik ubi jalar putih, kuning, orange maupun ungu. Antara lain pengolahan ubi jalar diklasifikasikan menjadi dua klasifikasi sebagai berikut :

1. Produk olahan makanan klasifikasi tradisonal/ klasik, seperti :timus, gethuk, keripik, klepon, kue talam, biji salak, kue lumpur, putumayang, bakpia, ondeonde, kue ku, kolakubi jalar dan lain-lain.

2. Produk olahan makanan klasifikasi modifikasi seperti : aneka roti, cake dan pastry seperti roti manis, brownies, donat, pastry, pie, cup cake, bolu gulung, soes, chiffon cake, sponge cake, dan aneka kue kering nastar, kastengel, putri salju dan lain-lain.

Pada kegiatan ini, kami Tim Pengabdian Kepada Masyarakat mendemokan dan mengajarkan beberapa jenis produk makanan olahan berbahan dasar ubi jalar kepada kelompok pengrajin dan ibu-ibu PKK RT.01 RW,24 Bibis Baru Kelurahan Nusukan kecamatan banjarsari Surakarta, seperti produk makanan olahantradisonal kue ku dan klepon serta produk olahan berbahan dasar ubi jalar yang merupakan produk olahan makanan modifikasi seperti cup cake, brownies kukus dan brownies panggang, chiffon cake, soes dan kue kering nastaar serta kastengel.

B. Teknik Pengemasan dan Pemasaran Produk Makanan Berbahan dasar Ubi Jalar Pada sesi akhir kegiatan Pengabdian Kepada Masyarakat, kami Tim Pengabdian Kepada Masyarakat STIE AUB Surakarta memberikan bekal berupa pelatihan teknik pengemasan dan pemasaran produk makanan berbahan dasar ubi jalar hasil pelatihan teknis pengolahan makanan berbahan dasar ubi jalar yang beberapa sesi sebelumnya telah selesai kami berikan

kepada kelompok pengrajin dan Ibu-ibu PKK RT. 01 RW. 24 Bibis Baru Kelurahan Nusukan Kecamatan Banjarsari Surakarta.

Pelatihan teknis meliputi teknis pengemasan produk makanan olahan yang baik dan higienis, sehingga produk makanan olahan lebih terlindung, awet dan dengan tampilan yang cantik dan menarik .Dengan pengemasan yang baik, higienis dan menarik diharapkan mampu menaikkan nilai ekonomis atau nilai jual produk makanan olahan tersebut.Selain kemasan yang baik, higienis dan menarik kami Tim Pengabdian Kepada Masyarakat juga membekali tentang prosedur pengajuan merk dagang untuk legalitas usaha yang dijalankan serta untuk tujuan pembedaan dari produk yang dihasilkan oleh pesaing. 


\section{DAMPAK}

Peningkatan kesejahteraan dapat dirasakan oleh keluarga dengan adanya tambahan pendapatan dengan menerapkan pelatihan ini dalam usaha rumahan (Home Industri)

\section{KESIMPULAN DAN SARAN}

\section{A. Kesimpulan}

Berdasarkan analisis situasi, permasalahan yang ada pada sasaran (kelompok pengrajin dan ibu-ibu PKK) di Kelurahan Nusukan Kecamatan Banjarsari Surakarta serta hasil pelaksanaan pelatihan teknik pengolahan dan pengemasan produk makanan berbahan dasar ubi di Bibis Baru kelurahanNusukan Kecamatan Banjarsari Surakarta, maka dapat disimpulkan

1. Kelompok pengrajin dan Ibu-ibu PKK Kelurahan Nusukan Kecamatan Banjarsari Surakarta sangat antusias mengikuti pelatihan teknik pengolahan dan pengemasan produk makanan berbahan dasar ubi, hal ini dapat dilihat dari semangat mereka berlatih melaksanakan tahap demi tahap dalam proses pembuatan beberapa jenis produk makanan olahan berbahan dasar ubi jalar yang Tim berikan dan banyaknya pertanyaan yang mereka ajukan.

2. Kelompok pengrajin dan Ibu-ibu PKK Bibis Baru Kelurahan Nusukan Kecamatan Banjarsari Surakarta sangat antusias mengikuti pelatihan teknik pengemasan dan pemasaran produk dan berharap ada pendampingan dari Tim PKM STIE AUB Surakarta tentang pemasaran aneka produk makanan olahanberbahas dasar ubi jalar.

\section{B. Saran}

1. Disarankan agar pada kegiatan Pengabdian Kepada Masyarakat berikutnya tidak hanya perwakilan setiap RW saja, tetapi setiap RT atau dasa wisma agar lebih mengena sasaran.

2. Disarankan pada kegiatan Pengabdian Kepada Masyarakat yang akan datang tidak hanya bahan dasraubi jalar saja, bisa dikembangkan dengan menggunakan bahan dasar lain yang cukup melimpah di lingkungan tersebut..

3. Disarankan kegiatan Pengabdian Kepada Masyarakat ini tidak berhenti hanya sampai disini saja, tetapi ada tindak lanjut sehingga terjalin kerjasama yang berkesinambungan antara Tim Pengabdian Kepada Masyarakat dengan Kelompok Pengrajin dn Ibu-ibu PKK serta bisa merangkul para pengusaha besar sebagai sasaran pelaksana dan menjadi orang tua angkat bagi kelompok pengrajin kecil hingga menengah melalui program Corporate Social Responsibility (CSR).

4. Disarankan pengabdian yang akan datang dapat dikembangkan pada ide- ide kreatif dan inovatif lainnya.

\section{REFERENSI}

https://cookpad.com Olahan Ubi jalar.

https://cookpad.com Olahan Ubi Jalar Kuning

kreatifikasi.blogspot.com: Welcome to my dreams: Olahan Makanan Serba Ubi Ungu

kueresep.com : 25 resep kue dari ubi jalar

m.beautynesia.id : 10 Resep Olahan Menu Pencuci Mulut dengan Ubi Jalarresepcaramasak.com : Cara Membuat kue Ubi Jalar Nikmat dan Enak- Resep

Cara Masak.

Resep-olahan-ubi-jalar.blogspot.com : Resep Kreatif Olahan Ubi Jalar

www.carakhasiatmanfaat.com: Kandungan Gizi Ubi Jalar dan Manfaatnya bagi

kesehatan-Cara KhasiatManfaat.

www.cicicookies.com 15 Resep Makanan Ubi Ungu

www.early.com Cara membuat jus segar ubi ungu 